\title{
0 processo de elaboração dos planos municipais de educação: saberes, diretrizes, políticas e práticas
}

\author{
The elaboration process of the municipal education plans: knowledge, guides, \\ policies, and practices \\ El proceso de elaboración de los planes municipales de educación: saberes, \\ directrices, políticas y prácticas
}

\section{MARIA ELIZA NOGUEIRA OLIVEIRA TATIANE OLIVEIRA SANTOS NASCIMENTO SILVIO CESAR NUNES MILITÃO}

\begin{abstract}
Resumo: O artigo objetiva analisar os Cadernos de Orientações (SASE/ MEC) produzidos com apoio técnico de destacadas organizações nacionais para subsidiar as esferas subnacionais no processo de elaboração dos Planos Municipais de Educação e desvelar a possível influência de tais orientações no referido processo e na atuação dos sujeitos nele envolvidos. Para tanto, confrontamos os dados da análise proposta com as pesquisas voltadas ao tema. O estudo revelou avanços significativos na condução das políticas educacionais, especialmente, no que diz respeito à consolidação da gestão democrática nos sistemas locais.
\end{abstract}

Palavras-chave: Planos Municipais de Educação; políticas educacionais; planejamento educacional; gestão de sistemas.

Abstract: The present paper aims to analyze the Guidance Notebooks (Board of Educational Systems/ Ministry of Education and Culture) developed with the technical support of outstanding Brazilian organizations in order to finance subnational spheres in the process of elaborating the County Education Planning and showing the presumed influence of such orientations in this process and the performance of the subjects involved. Therefore, data of the proposed analysis were compared with the researches related to the topic. The study demonstrated significant advances in the management of educational policies, especially regarding the consolidation of democratic management in local systems.

Keywords: County Education Planning; Education policies; Education planning; System management. 
Resumen: El artículo objetiva analizar los Cuadernos de Orientaciones (SASE/ MEC) producidos con apoyo técnico de destacadas organizaciones nacionales para subsidiar las esferas subnacionales en el proceso de elaboración de los Planes Municipales de Educación y desvelar la posible influencia de tales orientaciones en el referido proceso y en la actuación de los sujetos en él involucrados. Para tanto, confrontamos los datos del análisis propuesto con las investigaciones sobre el tema. El estudio reveló avances significativos en la conducción de las políticas educativas, especialmente, en lo que se refiere a la consolidación de la gestión democrática en los sistemas locales.

Palabras-clave: Planes municipales de educación; políticas educativas; planificación educativa; gestión de sistemas.

\section{INTRODUÇÃO}

$\mathrm{O}$ artigo apresenta dados de uma pesquisa que analisou o processo de elaboração dos Planos Municipais de Educação (PME), parte integrante do processo de execução do atual Plano Nacional de Educação (PNE) 2014-2024', aprovado em 25 de junho de 2014 por meio da Lei no 13.005. Os dados e análises que apresentaremos foram produzidos em uma das etapas da pesquisa em que analisamos os Cadernos de Orientações formulados pela Secretaria de Articulação dos Sistemas de Ensino (SASE) ${ }^{2}$ e pelo Ministério da Educação (MEC), em parceria com diversas instituições, com a finalidade de subsidiar as redes municipais na elaboração de seus planos educacionais. Com o objetivo de desvelar a possível influência das orientações oficiais - materializadas nos Cadernos de Orientações (SASE/MEC) - no processo de elaboração dos PME e na atuação dos sujeitos nele envolvidos, realizamos um estudo bibliográfico em que confrontamos os dados da análise documental com as pesquisas referentes aos PME. O estudo tomou como referência artigos publicados em revistas qualificadas da área da Educação (Qualis A1 a A2) entre os anos de 2014 a 2018.

$\mathrm{Na}$ primeira parte do texto, realizaremos um resgate histórico dos agentes que participaram da elaboração dos Cadernos Oficiais que orientaram os municípios na elaboração dos PME, para, em seguida, procedermos à análise descritiva do material, de maneira que possamos conhecer as concepções de gestão e os saberes engendrados pelos sujeitos que atuaram no processo de elaboração dessas diretrizes assim como as possíveis influências exercidas sobre eles nesse

\footnotetext{
1 O PNE 2014-2024 foi aprovado (sem vetos) pela então Presidente da República Dilma Rousseff após quase quatro anos de tramitação no Congresso Nacional - e possui 20 Metas e 254 Estratégias.

2 A SASE foi criada em 2011 como demanda da Conferência Nacional de Educação de 2010, tendo como objetivo principal consolidar o Sistema Nacional de Educação (SNE) por meio de estratégias consubstanciadas no Plano Nacional de Educação.
} 
contexto. Na última seção, apresentaremos a análise das pesquisas voltadas ao estudo dos processos de elaboração dos PMEs, com o objetivo explicitado anteriormente.

\section{ORIENTAÇÕES PARA A ELABORAÇÃO DOS PME(s): QUEM FORAM SEUS AGENTES?}

Nesta seção, o foco se volta aos agentes que compuseram as equipes responsáveis pela produção dos materiais de orientação que subsidiaram as redes de ensino nos processos de elaboração dos planos municipais de educação. Apesar de não ser apontada qualquer referência explícita aos autores do conteúdo desses materiais, na apresentação do caderno "Planejando a Próxima Década: alinhando os planos de educação", são citadas, na construção do material, contribuições de reconhecidas entidades e organizações, como a Associação Nacional de Política e Administração da Educação (ANPAE), o Conselho Nacional de Educação (CNE), a União dos Conselhos Municipais de Educação (UNCME) e o Fórum dos Conselhos Estaduais de Educação (FNCE). No que diz respeito à União dos Dirigentes Municipais de Educação (UNDIME) e ao Conselho Nacional de Secretários de Educação (CONSED), foi conferido destaque ao diálogo intenso estabelecido entre esses dois órgãos “com o Ministério da Educação sobre a responsabilidade de fazer deste próximo decênio um virtuoso marco no destino do País". (BRASIL, 2014b)

Fundadas entre os anos de 1931 a 1992, em diferentes contextos, as agências supracitadas possuem forte tradição de atuação e influência no delineamento das políticas educacionais brasileiras. Em uma perspectiva histórica ${ }^{3}$, o CNE foi a primeira dentre elas a ser fundada, em 1931 - após diversos intentos infrutíferos - no bojo da Reforma Francisco Campos (Decreto no 19.850), como órgão consultivo cuja função era assessorar os trabalhos ministeriais no período de transição entre a República Oligárquica e a Era Varguista, convertendo-se em espaço de fortes disputas entre grupos de interesse que dominavam o cenário político nacional (ROMANELLI, 2006; SILVA, 2005). Nos anos posteriores, até a promulgação da primeira Lei de Diretrizes e Bases da Educação Nacional (LDB) - Lei no 4.024/61 - num cenário marcado por intensos embates entre grupos conservadores e progressistas, o CNE manteve a função de assessoramento, registrando-se, durante todo esse período, a significativa presença de profissionais

3 Cumpre informar que remonta ao Império a existência de conselhos de educação no Brasil (BORDIGNON, 2009). 
especializados, sobretudo os que atuavam no ensino superior, estando ausentes "representantes do magistério ou de pessoal ligado ao ensino primário ou profissional” (ROMANELLI, 2006, p.140).

Com a promulgação da LDB/61, sancionada em 20 de dezembro do referido ano pelo então Presidente da República João Goulart, o CNE foi substituído pelo Conselho Federal de Educação (CFE), colegiado com maior representatividade dos demais níveis de ensino do magistério profissional e particular das diversas regiões do país, elevando seu grau de importância em nível nacional, deixando de ser um órgão de assessoramento para se tornar um órgão de direção. (ROMANELLI, 2006).

Instalado no país em 12 de fevereiro de 1962, o CFE

Recebeu funções que abrangiam desde as questões macro, como a formulação da política nacional de educação e a normatização sobre o sistema federal de ensino, até as demandas particulares, institucionais e individuais, como autorização e reconhecimento de cursos, aprovação de estatutos e regimentos, credenciamento de professores, convalidação de estudos e tantas outras de um elenco de três dezenas. Seus 24 conselheiros eram de livre nomeação do Presidente da República (BORDIGNON, 2009, p. 56).

Após funcionar por pouco mais de três decênios, o CFE foi extinto e sucedido pelo CNE, por meio da Medida Provisória no 661, de 18 de outubro de 1994. Depois da edição da Lei no 9.131, de 24 de novembro de 1995, o CNE foi definitivamente instituído, adotando a composição na qual se apresenta na atualidade.

Além de criar o CFE, a LDB/61 dispôs sobre a organização dos Conselhos Estaduais de Educação (CEE), instituindo-os como órgãos primordiais para a consolidação do sistema nacional de educação. Apesar de preconizados na década de $1930^{4}$, os CEEs ainda não haviam sido oficializados por meio de regulamentação federal que dispusesse a respeito de sua organização e de suas atribuições. De maneira análoga à organização do CFE, a Lei no 4.024/61 determinou que os CEE fossem constituídos por membros nomeados por autoridade competente "incluindo representantes dos diversos graus de ensino e do magistério oficial e particular, de notório saber e experiência, em matéria de educação" (BRASIL, 1961), mantendo uma relação de articulação com o

4 A Constituição de 1934, sob a influência do Manifesto dos Pioneiros, também previa a existência de conselhos de educação, nos âmbitos nacional (Art. 152) e estaduais (Art. 152, Parágrafo Único) (OLIVEIRA et al., 2006). 
Conselho Federal. Em termos de atribuições, além das funções normativas e de assessoramento, os CEE passaram a atuar como órgãos de planejamento e delineamento de políticas educacionais no âmbito dos estados, acordadas com os planos e projetos nacionais.

Assim, embora já previstos na Carta Magna de 1934, os CEE “Somente foram efetivamente criados e passaram a funcionar a partir da aprovação da primeira LDB (Lei n ${ }^{\circ}$ 4.024/61). Entre 1962 e 1965 todos os estados criaram seus conselhos de educação". (BORDIGNON, 2009, p. 57).

$\mathrm{Na}$ mesma década em que se instituíram os conselhos de educação federal e estaduais, emergiu outra importante entidade no âmbito da sociedade civil organizada, a ANPAE. Criada em 1961 por renomados professores de pesquisa, ensino e exercício de administração ${ }^{5}$ - sob a denominação de "Associação Nacional de Professores de Administração Escolar" -, a ANPAE emerge de demandas nacionais que, durante as décadas de 1940 e 1950 já haviam sido apontadas por outros pioneiros da administração educacional no país, como Lourenço Filho e Antônio Carneiro Leão, tendo em vista a "necessidade de sistematizar conhecimentos e práticas de administração do ensino, de defender e valorizar os pesquisadores e docentes de gestão escolar nos meios acadêmicos". (SANDER, 2007, p. 3)

Neste contexto, que representa a primeira fase da associação, os debates ocorridos no âmbito dos Simpósios Brasileiros da ANPAE (1961, 1963, 1966 e 1969) anunciavam duas funções primordiais da associação: fortalecer os estudos acadêmicos em administração escolar e formar dirigentes educacionais, abrindo espaço para um novo campo de pesquisa e intervenção educacional.

No quinto Simpósio, ocorrido em 1971, inaugura-se a segunda fase da entidade em decorrência de sua abertura para a participação de demais especialistas e profissionais da educação refletida na mudança de sua nomenclatura para 'Associação Nacional de Profissionais de Administração'. Neste mesmo ano, registram-se no cenário da educação nacional dois acontecimentos importantes: a promulgação da Lei $\mathrm{n}^{0} 5.692 / 71$, que altera substancialmente a estrutura da educação brasileira instituída pela LDB/61, e a criação dos Conselhos Municipais

\footnotetext{
5 De acordo com Benno Sander (2007, p.3), fizeram parte da fundação da ANPAE os seguintes professores e intelectuais brasileiros: Anísio S. Teixeira e Paulo de Almeida Campos, do Rio de Janeiro; Antonio Pithon Pinto, da Bahia; José Querino Ribeiro, Carlos Corrêa Mascaro e Moysés Brejón de São Paulo; Lauro Esmanhoto, do Paraná; Lirêda Facó, do Ceará; Antonieta Bianchi, de Minas Gerais; Merval Jurema, de Pernambuco; Antônio Gomes Moreira Júnior, do Pará; e José Gomes de Campos, Padre Theobaldo Frantz, Irmão Faustino João e Francisco Schuch, do Rio Grande do Sul.
} 
e Educação (CME) ${ }^{6}$ que, em decorrência dessa nova estrutura estabelecida pela legislação de 1971, assumem a função de organizar o ensino de primeiro grau colocado pela nova lei sob responsabilidade dos municípios.

Entre a metade da década de 1970 e 1980, quando os debates em torno da redemocratização do sistema político se intensificaram, a ANPAE, juntamente com as demais entidades educacionais nacionalmente instituídas, ampliou seus estudos para a dimensão educacional, inaugurando sua terceira fase marcada pela inserção de pesquisadores pós-graduados em administração educacional na direção de suas atividades. Essa fase abriu caminhos para o quarto ${ }^{7}$ momento da associação, marcado pelo enfoque sociopolítico (SANDER, 2007, p. 5). Tratouse de um período importante em que os debates ganharam forte teor acadêmico, que culminou no lançamento, em 1983, da Revista Brasileira de Administração da Educação, atualmente de Revista Brasileira de Política e Administração da Educação (RBPAE), ainda hoje um dos veículos mais importantes de disseminação de conhecimentos e experiências relacionados à política e gestão educacionais brasileiras. Assim, ainda sob vigência do regime militar, a ANPAE converteu-se em "um dos espaços abertos para a atuação dos pensadores de vanguarda no campo da educação, protagonistas da resistência política e do pensamento crítico no campo da gestão da educação", contribuindo, essencialmente, para o processo de democratização da educação brasileira.

A 'orientação político-pedagógica' assumida pela ANPAE, consagrada por sua produção científica e seu envolvimento na formulação de políticas educacionais, resultou em diversas mudanças no interior da Associação, que, em 1996, assumiu a sua quinta denominação "Associação Nacional de Política e Administração da Educação", refletindo "o seu compromisso com a construção do conhecimento e das práticas no campo da gestão democrática da educação brasileira" (SANDER, 2007, p. 8).

Em tempos de esgotamento do regime militar e de redemocratização do país, cuja culminância foi a aprovação da Constituição Federal de 1988, na qual se estabeleceu o regime de colaboração entre a União, os estados e os municípios,

6 Não obstante experiências anteriores e pioneiras de criação de colegiados locais de educação no Brasil, a formalização da existência de tal colegiado por legislação de âmbito nacional vem ocorrer somente com a edição da Lei n ${ }^{\circ}$ 5.692/71 que, em seu artigo 71, previa: “Os Conselhos Estaduais de Educação poderão delegar parte de suas atribuições a Conselhos de Educação que se organizem nos Municípios onde haja condições para tanto" (BRASIL, 1971).

$7 \quad$ Na terceira (1976) e quarta (1980) fases da associação, ela recebeu os nomes de "Associação Nacional de Profissionais de Administração Educacional" e "Associação Nacional de Profissionais de Administração da Educação", respectivamente. 
foram criadas novas organizações que, assim como a ANPAE, atuaram na elaboração dos materiais de orientação para a elaboração dos planos educacionais, com destaque para o CONSED e a UNDIME, ambos fundados em 1986.

Criadas na efervescência dos movimentos em defesa da democracia, essas entidades se fundamentaram nos preceitos constitucionais que conferem autonomia aos sistemas de ensino e ajudaram a introduzir os debates em torno da descentralização e da municipalização que, progressivamente, foram sendo assumidas pelo MEC como políticas públicas nacionais ${ }^{8}$. Dessa maneira, ao apoiar, com fins estratégicos, as demandas do CONSED e da UNDIME, o MEC consolidou essas entidades como importantes instâncias representativas dos poderes públicos municipais nos processos de discussão, formulação e implementação das políticas educacionais (NEVES, 1994).

A partir de meados da década de 1990, quando se assistiu à aprovação da vigente Lei de Diretrizes e Bases da Educação Nacional (Lei no 9.394/96), até meados da segunda década dos anos 2000, a ANPAE, juntamente com as demais entidades que participaram ativamente do processo de elaboração das políticas nacionais nas três últimas décadas, assumiu o paradigma da gestão democrática "como estratégia organizacional e administrativa para o exercício da cidadania e a promoção dos direitos humanos na educação e na sociedade.” (SANDER, 2007, p. 7).

Entretanto, num cenário contemporâneo caracterizado por fortes retrocessos políticos e sociais, ajuste fiscal e constantes ataques à democracia - que se inicia no governo federal ilegítimo e antipopular de Michel Temer "instalado em consequência de um golpe jurídico-midiático-parlamentar" (SAVIANI, 2018, p. 45) de meados de 2016, e que tem continuidade no governo federal liberal-conservador de Jair Bolsonaro, atualmente em curso - os ideais políticos e educacionais anteriormente aludidos encontram-se em risco, bem como a efetiva materialização das metas do PNE 2014-2024 se mostra substancialmente comprometida.

Ao instituir novo regime fiscal e congelar por vinte anos os gastos públicos, a Emenda Constitucional no 95, de 15 de dezembro de 2016, pode representar, na prática, a "morte" do PNE 2014-2024 e também do plano subsequente, como

8 Neste artigo, não apresentaremos as análises referentes aos efeitos do processo de descentralização no cenário educacional brasileiro. Neste tópico, nosso objetivo se restringe a descrever, brevemente, o histórico de fundação das principais entidades envolvidas no processo de elaboração das orientações que subsidiaram a elaboração dos planos municipais de educação. Entretanto, indicamos a leitura do texto da autora Maria de Fátima Félix Rosar, intitulado "A municipalização como estratégia de descentralização e de desconstrução do sistema educacional brasileiro", publicado no livro "Gestão Democrática da Educação: desafios contemporâneos" organizado por Dalila Andrade de Oliveira, publicado pela Editora Vozes. 
bem observa Amaral (2016, p. 654): “esses 20 anos, que se estenderão até 2036, abrangerão o período do PNE [vigente] e também o período do próximo PNE que deverá ser o de 2025 a 2035".

A edição da Portaria n ${ }^{\circ}$ 577, de 27 de abril de 2017, ao estabelecer unilateralmente nova configuração à composição do Fórum Nacional de Educação (FNE) ${ }^{9}$, excluindo de tal colegiado a representatividade de importantes entidades da educação, como a ANPEd e a própria ANPAE, também veio concorrer para obstaculizar a materialização do PNE em vigência, representando "uma ameaça, sobretudo, à implementação das políticas dispostas na LDB/1996 e nas 20 metas e 254 estratégias do Plano" (BRZEZINSKI, 2018, p. 15).

Frente a tal ataque e como forma de resistência ativa à portaria supracitada, históricas entidades educacionais que compunham o FNE abdicaram da correspondente representação no colegiado e criaram o Fórum Nacional Popular de Educação (FNPE) ${ }^{10}$, cujo objetivo principal é pressionar o governo federal a colocar em prática as metas do plano nacional, realizando, com ampla participação da sociedade civil, o monitoramento e a avaliação desse processo.

Diante das ameaças que o atual contexto político representa à materialização do PNE, procuramos, neste tópico, apresentar o processo histórico de formação das principais agências que atuaram na elaboração das diretrizes voltadas à orientação do processo de elaboração dos planos nos municípios, procurando evidenciar a relação entre esse processo e a democratização dos espaços decisórios onde, desde então, delineiam-se as políticas educacionais brasileiras.

\section{CADERNOS DE ORIENTAÇÕES PARA A ELABORAÇÃO DOS PLANOS MUNICIPAIS DE EDUCAÇÃO: SABERES E PRÁTICAS}

Ao acessarmos o site $e^{11}$ do PNE, observamos, na parte superior da tela, a aba "publicações", onde estão disponibilizados, para download, alguns materiais em que se incluem os três Cadernos, objetos de nossa análise, voltados à "Elaboração ou Adequação dos Planos Subnacionais de Educação".

Constituído após e em atendimento à demanda da primeira edição da Conferência Nacional de Educação (CONAE), o FNE - instituído originalmente pela Portaria no 1.407, de 14 de dezembro de 2010 - tem como principais atribuições a organização das vindouras conferências educacionais (em âmbitos municipal, estadual e nacional) e o imprescindível acompanhamento da implementação das metas instituídas no PNE.

10 O FNPE realizou em Belo Horizonte - MG, de 24 a 26 de maio de 2018, a Conferência Nacional Popular de Educação (CONAPE).

11 http://pne.mec.gov.br/publicacoes/itemlist/category/3-elaboracao-e-adequacao. Último acesso em 04 de janeiro de 2019. 
O primeiro caderno denominado "Planejando a próxima década: Alinhando os Planos de Educação" (BRASIL, 2014b), compõe-se de 24 páginas e, logo em sua apresentação, propõe aos gestores a ampliação da visão sistemática de suas respectivas redes para a elaboração de metas comuns, em parceria e colaboração com os demais entes federados, ressaltando a valorização de representações governamentais e sociais na elaboração desse documento e a importância do pacto federativo como base essencial para uma educação de qualidade.

O caderno acentua ainda a leitura da realidade local como base para o delineamento de políticas públicas e enfatiza que "a pactuação deve começar na fase de elaboração participativa das metas e estratégias" (BRASIL, 2014b, p.12), reforçando que os acordos devem ser firmados, fundamentalmente, nas diretrizes do PNE 2014-2024, estabelecidas com base no diagnóstico da educação nacional construído com amplas contribuições de conselhos e outros órgãos de participação social.

$\mathrm{Na}$ quinta seção, intitulada 'Elaboração ou adequação, aprovação, acompanhamento e avaliação dos planos de educação', apresenta a estrutura do plano quanto à elaboração ou adequação dos planos já aprovados na vigência do PNE (2001-2010), apontando que 12 planos estaduais e 1.600 planos municipais foram aprovados, por Lei, na vigência do PNE anterior. Na sequência, define uma proposta de trabalho para a elaboração do PNE 2014-2024 sintetizada nos seguintes itens:

a) procedimentos, roteiros, atividades e sugestões para efetivação do trabalho nas instituições educativas (escolas, instituições de ensino superior e demais instituições); [...] b) mobilização da comunidade, incluindo o envio de documento base para a elaboração ou adequação do plano; [...] c) realização de reuniões com as equipes e comissões encarregadas do processo de mobilização e elaboração ou adequação; [...] d) indicação de realização de seminários, simpósios, dentre outros; [...] e) organização de equipe de sistematização; [...] f) previsão de mecanismos de acompanhamento e avaliação; [...] g) previsão de encaminhamento de projeto de lei para o legislativo. (BRASIL, 2014b, p.15)

Apreende-se, portanto, que o material se assenta em uma concepção de planejamento democrático, apresentado como um movimento favorável à efetivação da soberania popular nos processos de tomada de decisões. Assinala ainda que, no processo de elaboração ou planejamento dos planos municipais, as comissões responsáveis deverão cuidar para que as metas e estratégias expostas no PNE 2014-2024, voltadas a atender diretrizes nacionais, constem nos planos locais, fato este que justifica o alinhamento dos planos ao documento nacional. Levando em consideração a concretização do chamado regime de colaboração, 
esse alinhamento, em certa medida, faz-se necessário; todavia, ele não pode ser confundido com cópia, comprometendo a autonomia dos municípios à efetivação das metas no contexto local, conforme se observou em pesquisa recente que analisou os planos municipais de diversos municípios. (NASCIMENTO, 2018)

O segundo caderno, denominado "Planejando a Próxima Década: conhecendo as 20 metas do Plano Nacional de Educação" (BRASIL, 2014c), foi publicado em um total de 63 páginas e organizado com uma apresentação e quatro seções. Na apresentação, são destacados alguns desafios na concretização do planejamento educacional, especialmente, no que diz respeito à construção de "formas orgânicas de colaboração entre os sistemas de ensino" (BRASIL, 2014c, p.5). A redação reforça ainda a necessidade de aproximar agentes públicos e sociedade civil, integrando-os na construção de propostas educacionais como também na agregação dos entes federados.

O terceiro caderno, publicado com o título 'O Plano Municipal de Educação: caderno de orientações’ (BRASIL, 2014d), possui 21 páginas e se subdivide em seis seções. Na primeira, apresenta três aspectos fundamentais do novo PNE (2014-2024): a vinculação dos recursos para o financiamento, com prevalência sobre os Planos Plurianuais (PPAs) ${ }^{12}$; o cumprimento dos fundamentos relevantes para articular o Sistema Nacional de Educação (SNE); e o pacto federativo. Além de destacar a relevância e a sintonia necessárias à elaboração ou adequação do PME, ressalta que o objetivo do caderno é subsidiar o trabalho dos Dirigentes Municipais, das equipes técnicas e das Comissões que coordenarão a materialização do documento municipal.

O caderno atribui aos dirigentes municipais, aos prefeitos e seus secretários, o papel de "importantes lideranças na construção das decisões que vincularão o projeto educacional com o projeto de desenvolvimento local" (BRASIL, 2014d, p.7), e pontua que o PME é a tradução das necessidades e capacidades educacionais, articuladas com os instrumentos de planejamento Plano Plurianual (PPA), a Lei de Diretrizes Orçamentárias $(\mathrm{LDO})^{13}$, a Lei Orçamentária Anual $(\mathrm{LOA})^{14}$ e o Plano de Ações Articuladas (PAR). Trata-se, portanto, de um projeto a ser elaborado por todos os órgãos educacionais do município e não apenas do órgão gestor da rede, devendo, assim, conquistar sua legitimidade ao considerar o percurso histórico,

12 Trata-se de um instrumento que visa a organizar e viabilizar a ação pública a fim de viabilizar os fundamentos e objetivos da República num período de quatro anos.

13 Um instrumento que "Fixa as grandes linhas no uso de recursos, estabelecendo metas e prioridades do PPA” (VIEIRA, 2014, p. 62).

14 Trata-se de um instrumento que "faz o detalhamento da destinação dos recursos ano a ano" (Ibidem). 
os aspectos socioculturais e ambientais, denominado 'intersetorialidade', em que todos os parceiros irão construir o plano e, posteriormente, compartilhar de seus benefícios.

$\mathrm{Na}$ sequência, em seção denominada 'O Plano em cinco etapas', são apresentadas as cinco ações para o encadeamento do trabalho: a) Definir e distribuir responsabilidades; b) Elaborar o Documento-Base; c) Promover um amplo debate; d) Redigir o Projeto de Lei; e) Acompanhar a tramitação na câmara municipal.

$\mathrm{Na}$ quarta seção do caderno, intitulada 'Algumas orientações técnicas', são disponibilizadas orientações referentes à elaboração do diagnóstico. $\mathrm{O}$ texto enfatiza a necessidade de se realizar a busca de dados nos portais da educação e reforça a importância de trabalhar tendo em vista a corresponsabilidade entre os entes federados.

Do exposto, constata-se que o documento reflete, em sua redação, a valorização de um planejamento participativo e democrático, refletindo os ideais defendidos, historicamente, pelas entidades que atuaram em sua elaboração. A orientação propõe a submissão do PME ao amplo debate, desde a elaboração do Documento-Base aos trâmites do Executivo, sendo fundamental a participação social e política de todos de forma a colaborar para as discussões e enriquecê-las, considerando as distintas visões e realidades sociais. Salienta ainda a importância do coletivo na supervisão, execução e materialização das metas propostas no plano municipal.

A seguir, apresentaremos a análise das pesquisas voltadas ao estudo dos processos de elaboração dos PME realizada com o objetivo de compreender possíveis influências das orientações oficiais na atuação dos sujeitos.

\section{O PROCESSO DE ELABORAÇÃO DOS PLANOS MUNICIPAIS DE EDUCAÇÃO: SABERES E PRÁTICAS}

O estudo que apresentaremos nesta seção buscou analisar o processo de elaboração dos PME a partir de dados de pesquisas publicados em revistas qualificadas da área da Educação (Qualis A1 e A2) entre os anos de 2014 e 2018. O levantamento dos textos se deu a partir das páginas eletrônicas das revistas enquadradas nos referidos estratos. No campo de busca, digitamos os termos "plano municipal de educação", "planos municipais" e "plano municipal" e chegamos a um total de nove artigos.

Constatamos que a produção do conhecimento relativa ao processo de elaboração dos PMEs é predominantemente recente, com a maioria dos artigos correspondentes (66,6\%) datando de 2017 e 2018. 
Por meio da leitura dos resumos dos trabalhos, observou-se que, em termos de objetivos, houve certa variação, sendo identificados quatro textos cujos autores voltaram-se, de forma mais específica, para a análise do processo de elaboração dos PME.

Com relação aos aspectos metodológicos, especificamente, os dados demostram que as pesquisas analisadas privilegiaram os estudos bibliográficos e documentais, tendo sido encontrada apenas uma pesquisa que empregou o estudo de caso e se valeu de um conjunto de instrumentos de coleta de dados (observações sistematizadas, análise documental e entrevistas abertas).

Tal predominância se explica, em certa medida, porque a pesquisa bibliográfica "Tem sido utilizada com grande frequência em estudos exploratórios ou descritivos [e] é sempre realizada para fundamentar teoricamente o objeto de estudo, contribuindo com elementos que subsidiam a análise futura dos dados obtidos" (LIMA; MIOTO, 2007, p. 40-44), assim como pelo fato de não ser pertinente analisar os processos de elaboração dos PME sem explorar detidamente estas fontes documentais. Porém, se as pesquisas bibliográficas e documentais se sobressaem, é também diminuta a quantidade de estudos sobre os processos de elaboração dos PME que dão visibilidade aos sujeitos diretamente envolvidos nos referidos processos.

Embora em nosso levantamento tenham sido encontrados quatro textos cujas análises se voltaram de forma mais acentuada ao processo de elaboração dos PME, ao tratar dos planos municipais, os textos, de modo geral, evidenciaram aspectos relevantes desse processo, permitindo-nos alcançar o objetivo proposto.

Dos nove textos encontrados, quatro foram publicados pelos mesmos autores, cujos dados de pesquisas provieram de investigações realizadas entre os períodos de 2012 a 2018, conforme informações contidas nos currículos acadêmicos dos autores disponibilizados pela Plataforma Lattes ${ }^{15}$.

Desse modo, os estudos encontrados abarcaram cidades pertencentes a seis estados brasileiros: Rio de Janeiro, São Paulo, Minas Gerais, Bahia, Rio Grande do Norte e Mato Grosso do Sul.

15 intitulado 'A ́́́ reformulações decorrentes do novo Plano Nacional de Educação (PNE)', que buscou analisar as dimensões estruturais e organizativas dos planos estaduais e municipais em consonância com o plano nacional de educação. No período de 2012 a 2015, a professora Alzira Batalha Alcântara integrou o projeto 'Os Planos Municipais de Educação (Brasil) e as Cartas Educativas Municipais (Portugal): perspectiva comparada entre as Regiões/Áreas Metropolitanas do Rio de Janeiro e do Porto', também coordenado pelo professor Souza, que analisou os planos municipais de 19 localidades da Região Metropolitana do Estado do Rio de Janeiro. 
Dos quatro artigos publicados correspondentes a pesquisas desenvolvidas no Estado do Rio de Janeiro, três deles no ano de 2017 e um em 2016, apenas dois trouxeram elementos relacionados ao processo de elaboração dos PME, sendo eles o texto de Souza (2017a), publicado na Revista

Estudos em Avaliação Educacional, e o texto de Souza e Alcântara (2017b), publicado na Revista Perspectiva. Nos artigos, os autores destacam algumas características referentes aos processos de elaboração dos PME; todavia, tratam apenas dos processos correspondentes aos planos elaborados entre os anos de 2001 a 2012, portanto, anteriores à publicação do atual PNE (BRASIL, 2014).

Ainda que os textos não correspondam a análises de planos mais atuais, cabe ressaltar a identificação de processos democráticos na elaboração dos planos municipais da RMRJ no período investigado pelos autores. Os dez municípios investigados, ressaltaram que houve 'participação da sociedade civil', embora não fosse possível identificar com precisão os atores sociais envolvidos. No que diz respeito ao processo, destaca-se o envolvimento dos Conselhos Municipais de Educação e a realização de encontros, reuniões e seminários como espaços privilegiados de construção, com destaque para quatro municípios que realizaram Conferências Municipais de Educação e um município que instituiu um Fórum Municipal de Educação como estratégia de elaboração.

No texto publicado na Revista Educação \& Realidade, os autores analisaram o caso de três municípios que compõem a Grande Região do $\mathrm{ABC}$ Paulista, onde a gestão democrática também se fez presente como paradigma dominante. Garcia e Bizzo (2018, p. 348) mencionam a criação, em todas as cidades, de "comissão especial com membros pertencentes aos vários segmentos que representavam a Secretaria de Educação, a rede privada de ensino, as instituições de ensino superior, os conselhos municipais de educação, entre outros". No que diz respeito aos limites do processo, os autores destacaram a 'falta de sensibilização da sociedade civil', 'a falta de conexão com a rede estadual de ensino', o 'curto espaço de tempo', a 'falta de análise do impacto orçamentário do plano' e a 'interferência de grupos relacionados à Igreja'. Com relação ao último elemento, os autores consideraram-no limitante, pois resultaram na alteração de todos os planos municipais da região, "sendo removidos quaisquer termos relacionados à ideologia de gênero ou à diversidade" (GARCIA; BIZZO, 2018, p. 353).

O estudo que analisou o processo de elaboração dos PME no Estado da Bahia foi o único que mencionou a colaboração da Rede de Assistência Técnica instituída pelo MEC por meio da SASE. A pesquisa foi realizada por meio do envio de questionários a membros do Comitê de Acompanhamento e Avaliação dos Planos Municipais (CAA). Os resultados indicaram 'êxito' em relação 
aos aspectos administrativo/organizacional do processo, evidenciando duas dimensões que os autores denominaram de "dimensão política" e "pedagógica". A primeira, relaciona-se à "melhoria do processo democrático de participação de diversas instâncias no processo, da transparência, da publicização das ações"; e a segunda, ao reconhecimento do preparo e da "existência de treinamento e assessoramento para a execução das atividades propostas, contribuindo para a compreensão do cenário de elaboração dos planos educacionais dos municípios baianos" (BORGES; CONCEIÇÃO, 2017, p. 131).

Publicado em 2015, o artigo da Revista Eccos analisa a elaboração do PME de Uberlândia (MG), aprovado em 12 de novembro de 2014, apenas quatro meses após a aprovação do PNE BRASIL, 2014, em decorrência do atraso na elaboração do documento municipal referente ao PNE anterior, BRASIL 2001, cujo início se deu em outubro de 2013, na gestão do prefeito Gilmar Machado (PT), que assumiu o mandato em janeiro do mesmo ano. A elaboração do PME se iniciou após a formação de uma comissão, no âmbito do Conselho Municipal de Educação, por intermédio da Secretaria Municipal de Educação, composta por membros pertencentes a ambos os órgãos municipais, cujos representantes incluíram representantes do Sindicato dos Professores da Rede Privada (Sinpro); representante da Superintendência da Juventude no CME; uma representante dos(as) professores(as) da Rede Municipal de Educação; e uma representante do Conselho Regional de Serviço Social. De acordo com os autores, a comissão foi coordenada por uma professora representante da Seção Sindical dos Docentes da Universidade Federal de Uberlândia (UFU).

$\mathrm{Na}$ análise dos autores, o processo foi conduzido de forma democrática, procurando "envolver o maior número de pessoas para a elaboração e consecução do PME” (FERREIRA; ANTUNES; MENDES, 2015, p. 35-36). Houve empenho da comissão com relação à sua função diagnóstica, propositiva e consultiva, propiciadas por meio da leitura e estudo coletivo de documentos que resultaram na elaboração de seis eixos temáticos, considerando-se o diagnóstico da educação municipal, utilizado como referência para a elaboração do plano. Os autores enfatizaram, ainda, a ativa participação da UFU nos debates e na defesa "da escola pública, gratuita e com financiamento totalmente público para as instituições públicas", demonstrando a importância da aproximação da universidade pública com a sociedade como forma de contribuir para as reflexões e aprimorar os instrumentos de luta pelo direito à educação. (Idem, p.37)

Experiências semelhantes às da cidade de Uberlândia foram vivenciadas nas cidades de Mossoró e Natal no Estado do Rio Grande do Norte e analisadas por Neto, Castro e Garcia (2016), em artigo publicado na RBPAE. No caso desses municípios, a revisão dos planos municipais se deu no contexto de implementação 
do Plano de Ações Articuladas (PAR) ${ }^{16}$, que, por meio de um sistema eletrônico padrão e integrado, passou a exigir das secretarias educacionais a realização de diagnósticos das redes de ensino que permitissem identificar a existência de planos municipais assim como os processos empreendidos para sua implementação e avaliação.

Realizadas a análise dos indicadores do PAR 2007-2011 dos municípios, os autores concluíram que, embora eles tivessem elaborado seus respectivos planos municipais, conforme determinado no PNE 2001, ambos "careciam de acompanhamento e reestruturação". Dessa maneira, foram desenvolvidas subações que incluíram a elaboração e aplicação de instrumentos de acompanhamento, execução e avalição do PNE e do PME, a qualificação de equipes, a implantação de planejamento estratégico, a capacitação dos sujeitos e a participação da sociedade civil. Concluído o processo, já no contexto de aprovação do atual PNE (2014-2024), os municípios elaboraram as novas edições de seus respectivos planos, concluindo que o PAR pode "vir a constituir-se em espaço ampliado da participação da sociedade civil e do exercício da autonomia dos municípios, visando a contribuir para a constituição do SNE". (NETO; CASTRO; GARCIA, 2016, p.61).

O artigo de Aranda, Perboni e Rodrigues (2018), em que os autores analisam os desdobramentos do plano municipal na gestão das políticas educacionais do município de Dourados (MS), registra a interferência do poder municipal na condução do processo de elaboração do PME, tanto no fomento à participação popular, conforme experiência vivenciada pelo município em 2002, quanto no seu entrave, quando o mesmo município passou por processos de reestruturações administrativas decorrentes da troca de prefeito em 2003. Assim, em consonância com as experiências dos municípios mineiro e potiguar, o município sul-mato-grossense já havia iniciado um processo de discussão voltado à elaboração de seu PME, no contexto do PNE de 2001. Entretanto, foi apenas em 2014, diante da obrigatoriedade estabelecida pelo PNE 2014-2024, que o plano de Dourados foi aprovado pela Lei Municipal n 3.904/2015.

Os autores não mencionam com detalhes de como se deu o processo de elaboração, mas indicam a participação da sociedade civil e de membros da Secretaria Municipal de Educação de Dourados na comissão responsável pela construção da redação do plano. Os autores esclarecem ainda, que a primeira

16 O Plano de Ações Articuladas é um instrumento de planejamento da educação por um período de quatro anos. É um plano estratégico de caráter plurianual e multidimensional que possibilita a conversão dos esforços e das ações do Ministério da Educação, das Secretarias de Estado e Municípios, num Sistema Nacional de Educação. A elaboração do PAR é requisito necessário para o recebimento de assistência técnica e financeira do MEC/FNDE, de acordo com a Resolução/CD/FNDE n 14 de 08 de junho de 2012. (Fonte: https://www. fnde.gov.br/programas/par/perguntas-frequentes. Acesso em: 08 de janeiro de 2019) 
versão do texto, redigida por seis subcomissões, foi apresentada à sociedade civil e à comunidade escolar e discutida por 18 meses antes de ser enviada para votação no legislativo. (ARANDA; PERBONI; RODRIGUES, 2018, p. 425)

Semelhante ao ocorrido nos municípios paulistas, os autores relatam que houve alteração no conteúdo do plano antes de ser aprovado, constatando-se a supressão de 71 estratégias, das 376 elaboradas pela comissão, "a maioria retirando prazos para o cumprimento de metas e suprimindo itens que são reivindicações antigas dos profissionais de Educação do município" (SIMTED/Dourados, 2015 apud ARANDA; PERBONI; RODRIGUES, 2018, p. 425).

A análise dos textos nos permite ensaiar algumas conclusões. Primeiramente, não foram identificados elementos que comprovassem a influência direta das diretrizes nacionais, materializadas nos Cadernos de Orientações SASE/MEC, no processo de elaboração dos planos municipais. Essa constatação aponta para a necessidade de empreendimento de novas pesquisas cujos métodos contemplem uma maior aproximação das Secretarias Municipais de Educação e abranjam contatos diretos com os sujeitos envolvidos no referido processo para obtenção dos correspondentes e imprescindíveis dados empíricos.

Com exceção do caso do Estado da Bahia, as pesquisas não explicitaram a interferência direta de assessores externos, permitindo-nos inferir que a participação das comunidades locais na definição das metas dos planos se deu em períodos anteriores à promulgação da Lei no 13. 005/2014, ainda no contexto de vigência do PNE (2001-2010), quando foram implementados programas e ações por parte do governo federal, com destaque para o Plano de Ações Articuladas (PAR/2007-2011), que estimularam a realização de diagnósticos referentes ao delineamento de metas consubstanciadas em planos educacionais, para que os governos federal, estaduais e municipais orientassem suas ações no sentido de consolidar o Sistema Nacional de Educação em regime de colaboração, conforme previsto nos princípios constitucionais que embasam o pacto federativo.

Conquanto o acesso aos Cadernos analisados neste artigo não tenha sido evidenciado nas pesquisas, os sistemas locais organizaram o processo de elaboração de seus planos de forma muito semelhante, permitindo-nos inferir a influência de orientações externas - consubstanciadas nos discursos oficiais disseminados em diversos sítios de acesso público - que, reiteramos, necessita ser estudada em maior profundidade por meio de métodos que não se restrinjam aos estudos bibliográficos e documentais.

Das análises dos autores, destacou-se a importância da determinação federal, expressa no Artigo $8^{\circ}$ da Lei 13.005/2014, que obrigou todos os municípios a instituírem seus respectivos planos municipais no prazo de um ano a partir da aprovação do PNE 2014-2024. Embora se reconheça o desafio imposto 
aos municípios para se adequarem aos prazos estabelecidos pelo poder central de forma arbitrária, conforme mencionamos anteriormente, muitos municípios já haviam dado início às ações voltadas à elaboração/adequação de seus planos locais. Esses fatores nos permitem considerar que o poder instituído expresso nas normas que emanam da esfera federal, apesar de seus limites, pode converterse em importante instrumento capaz de colocar em prática novas formas de se fazer política, valorizando ações coletivas e processos democráticos de tomada de decisões.

Foi unânime a afirmação de que os municípios adotaram a gestão democrática como paradigma dominante na organização dos processos. Os textos analisados nos permitem, portanto, reafirmar a importância dos planos municipais como instrumento de democratização da educação em sentido amplo e de efetivação do Sistema Nacional de Educação. Indubitavelmente, o PNE representa uma conquista histórica de toda a sociedade brasileira e, fundamentalmente, dos agentes que participaram do delineamento das diretrizes que nortearam as ações dos elaboradores dos planos locais. Por esse motivo, o PNE representa muito mais que uma política pública educacional; ele representa um avanço substancial na maneira de conduzir a política. Nas palavras de Sander (2007), uma "filosofia política" que há muito tempo vinha sendo gestada e cujos frutos somos agora capazes de reconhecer.

\section{REFERÊNCIAS}

AMARAL, Nelson Cardoso. PEC 241/55: a "morte" do PNE (2014 2024) e o poder de diminuição dos recursos educacionais. RBPAE - v. 32, n. 3, p. 653 - 673 set./dez. 2016.

ARANDA, Maria Alice de Miranda; PERBONI, Fábio; RODRIGUES, Evally Solaine de Souza. O Plano Municipal de Educação de Dourados - MS: política, gestão e participação. Revista Diálogo Educacional, Curitiba, vol. 18, n. 57, abr./jun. 2018. p. 416-436.

BORDIGNON, Genuíno. Gestão da educação no município: sistema, conselho e plano. São Paulo: Editora e Livraria Instituto Paulo Freire, 2009.

BORGES, Moacir Freitas; CONCEIÇÃO, Sérgio Henrique. Planos Municipais de Educação (PMEs): restrições políticas, econômicas e metodológicas no processo de elaboração e acompanhamento em municípios baianos. Educação Unisinos, vol. 2, no 2. maio/agosto 2017. p.124-136. 
BRASIL. Lei 13.005, de 24 de junho de 2014. Aprova o Plano Nacional de Educação - PNE e dá outras providências. Diário Oficial da União. Brasília, DF: Poder Legislativo, 26 jun. 2014a, p. 01, Edição Extra. Disponível em: http:/ / www.planalto.gov.br/ccivil_03/_Ato2011-2014/2014/Lei/L13005.htm Acesso em: 15 de março de 2019.

BRASIL. Ministério da Educação. Secretária de Articulação com os Sistemas de Ensino. Cadernos Planejando a Próxima Década: alinhando os Planos de Educação. Brasília, DF: MEC/SASE, 2014b.

BRASIL. Ministério da Educação. Secretária de Articulação com os Sistemas de Ensino. Cadernos Planejando a Próxima Década: conhecendo as 20 Metas do Plano nacional de Educação. Brasília, DF: MEC/SASE, 2014c.

BRASIL. Ministério da Educação. Secretária de Articulação com os Sistemas de Ensino. Cadernos Planejando a Próxima Década: plano Municipal de Educação: caderno de orientações. Brasília, DF: MEC/SASE, 2014d.

BRASIL. Lei 5.692, de 11 de agosto de 1971. Fixa Diretrizes e Bases para o ensino de $1^{\circ}$ e $2^{\circ}$ graus, e dá outras providências. Diário Oficial da União Seção 1 - 12/8/1971, Página 6377 (Publicação Original). Disponível em: https:/ / www2.camara.leg.br/legin/fed/lei/1970-1979/lei-5692-11-agosto-1971-357752publicacaooriginal-1-pl.html Acesso em: 21 de junho de 2019.

BRASIL. Lei 4.024, de 20 de dezembro de 1961. Fixa as Diretrizes e Bases da Educação Nacional. Diário Oficial da União - Seção 1 - 27/12/1961, Página 11429 (Publicação Original). Disponível em: https://www2.camara.leg.br/legin/ fed/lei/1960-1969/lei-4024-20-dezembro-1961-353722-publicacaooriginal-1-pl. html Acesso em: 21 de junho de 2019.

BRASIL. Decreto $\mathbf{n}^{\mathbf{0}} \mathbf{1 9 . 8 5 0}$, de 11 de abril de 1931. Cria o Conselho Nacional de Educação. Diário Oficial - 15/4/1931, Página 5799 (Publicação Original). Disponível em: https://www2.camara.leg.br/legin/fed/decret/1930-1939/ decreto-19850-11-abril-1931-515692-publicacaooriginal-1-pe.html Acesso em: 06 de agosto de 2019. 
BRASIL. Medida Provisória $\mathrm{n}^{\circ}$ 661, de 18 de outubro de 1994. Altera dispositivos da Lei $\mathrm{n}^{\circ}$ 4.024, de 20 de dezembro de 1961, e da Lei $\mathrm{n}^{\circ}$ 5.540, de 28 de novembro de 1968, e dá outras providências. Diário Oficial da União - Seção 1 - 19/10/1994, Página 15799 (Publicação Original). Disponível em: https://www2.camara.leg.br/legin/fed/medpro/1994/medidaprovisoria-66118-outubro-1994-377097-publicacaooriginal-1-pe.html Acesso em: 06 de agosto de 2019.

BRASIL. Lei $\mathbf{n}^{\circ}$ 9.131, de 24 de novembro de 1995. Altera dispositivos da Lei n ${ }^{\circ} 4.024$, de 20 de dezembro de 1961, e dá outras providências. Diário Oficial da União - Seção 1 - Edição Extra - 25/11/1995, Página 19257 (Publicação Original). Disponível em: https://www2.camara.leg.br/legin/fed/lei/1995/ lei-9131-24-novembro-1995-372496-norma-pl.html Acesso em 06 de agosto de 2019.

BRASIL. Constituição da República dos Estados Unidos do Brasil, de 16 de julho de 1934. Diário Oficial da União - Seção 1 - Suplemento - 16/7/1934, Página 1 (Publicação Original). Disponível em: https://www2.camara.leg. br/legin/fed/consti/1930-1939/constituicao-1934-16-julho-1934-365196publicacaooriginal-1-pl.html Acesso em 06 de agosto de 2019.

BRASIL. Lei $\mathbf{n}^{\circ}$ 9.394, de 20 de dezembro de 1996. Estabelece as diretrizes e bases da educação nacional. Diário Oficial da União - Seção 1 - 23/12/1996, Página 27833 (Publicação Original). Disponível em: https://www2.camara. leg.br/legin/fed/lei/1996/lei-9394-20-dezembro-1996-362578-norma-pl.html Acesso em 06 de agosto de 2019.

BRASIL. Emenda Constitucional no 95, de 15 de dezembro de 2016. Altera o Ato das Disposições Constitucionais Transitórias, para instituir o Novo Regime Fiscal, e dá outras providências. Diário Oficial da União - Seção 1 - 16/12/2016, Página 2 (Publicação Original). Disponível em: https://www2.camara.leg.br/ legin/fed/emecon/2016/emendaconstitucional-95-15-dezembro-2016-784029norma-pl.html Acesso em 06 de agosto de 2019. 
BRASIL. Ministério da Educação. Conselho Deliberativo do Fundo Nacional de Desenvolvimento da Educação (FNDE). Resolução/CD/FNDE n 14 de 08 de junho de 2012. Estabelece os critérios para o apoio técnico e financeiro às redes públicas de educação básica dos Estados, Municípios e Distrito Federal, no âmbito do Plano de Ações Articuladas (PAR). Disponível em: https://www.fnde. gov.br/index.php/acesso-a-informacao/institucional/legislacao/item/3524resolu\%C3\%A7\%C3\%A3o-cd-fnde-n\%C2\%BA-14-de-08-de-junho-de-2012 Acesso em 06 de agosto de 2019.

BRASIL. Ministério da Educação. Portaria no 577, de 27 de abril de 2017. Dispõe sobre o Fórum Nacional de Educação. Diário Oficial da União - Edição 81, Seção 1, p. 39. Disponível em: http://www.in.gov.br/materia/-/asset_publisher/ Kujrw0TZC2Mb/content/id/20184519/do1-2017-04-28-portaria-n-577-de-27de-abril-de-2017-20184461 Acesso em 06 de agosto de 2019.

BRZEZINSKI, Íria. Apresentação. In: BRZEZINSKI, Íria (Org.). LDB 1996 vinte anos depois: projetos educacionais em disputa. São Paulo: Cortez, 2018. p. 13-26.

DOURADOS. Lei n 3.904, de 23 de junho de 2015. Aprova o Plano Municipal de Educação do Município de Dourados do Estado do Mato Grosso do Sul, e dá outras providências. Disponível em: http://www.dourados.ms.gov.br/wpcontent/uploads/2015/11/PME-Dourados-2015-Vers\%C3\%A3o-Final-1.pdf Acesso em 6 de agosto de 2019.

FERREIRA, Jorgetânia da Silva, ANTUNES, Marina Ferreira de Souza, MENDES, Olenir Maria. O Plano Nacional de Educação: desafios a partir da construção do Plano Municipal de Educação de Uberlândia. EccoS: Revista Científica, São Paulo, n. 36, jan./abr. 2015. p. 29-47.

GARCIA, Paulo Sérgio; BIZZO, Nélio. O Processo de Elaboração dos Planos Municipais de Educação na Região do Grande ABC. Educação \& Realidade, Porto Alegre, vol. 43, n. 1, jan./mar. 2018. p. 337-362.

LIMA, Telma Cristiane Sasso de; MIOTO, Regina Célia Tamaso. Procedimentos metodológicos na construção do conhecimento científico: a pesquisa bibliográfica. Rev. Katál. Florianópolis v. 10 n. esp. p. 37-45 2007. 
NASCIMENTO, Tatiane Oliveira Santos. O Plano Nacional de Educação e os desafios para a elaboração dos Planos Municipais de Educação. 2018. 111 f. Dissertação (Mestrado em Educação) - Programa de Pós-Graduação em Educação, Universidade do Oeste Paulista, Presidente Prudente, 2018.

NETO, Antônio Cabral; CASTRO, Alda Maria Duarte Araújo; GARCIA, Luciane Terra dos Santos. Plano Municipal de Educação: elaboração, acompanhamento e avaliação no contexto do PAR. RBPAE. vol. 32, n. 1, jan./abr. 2016. p. 47-67.

NEVES, Lúcia Maria Wanderley. Educação e política no Brasil de hoje. São Paulo: Cortez, 1994.

OLIVEIRA, Cleiton de et al. Conselhos Municipais de Educação: um estudo na região metropolitana de Campinas. Campinas, SP: Alínea, 2006.

OliveIRA, Dalila Andrade de. (Org). Gestão Democrática da Educação: desafios contemporâneos. $11^{\mathrm{a}}$ ed. Petrópolis: Vozes, 2009.

ROMANELLI, Otaíza de Oliveira. História da Educação no Brasil (1930/1973). 30ª . ed. Petrópolis: Vozes, 2006.

SANDER, Benno. Introdução à história da ANPAE como sociedade civil no campo da educação. In: Simpósio Brasileiro de Política e Administração da Educação, Porto Alegre, 2007.

. "A genealogia do conhecimento da administração da educação do Brasil e o papel da Anpae como entidade da sociedade civil ". Goiânia: ANPAE, s.d. Disponível em: https://www.anpae.org.br/website/documentos/ estudos/estudos_01.pdf Acesso em: 14 mar. 2019.

SAVIANI, Dermeval. Sistema Nacional de Educação e Regime de Colaboração. In: BRZEZINSKI, Íria (Org.). LDB 1996 vinte anos depois: projetos educacionais em disputa. São Paulo: Cortez, 2018. p. 27-46.

SILVA, Andréia Ferreira da. O Conselho Nacional de Educação e as políticas de privatização da Educação Superior no governo de FHC. Inter-Ação: Revista da Faculdade de Educação da UFG, Goiânia, ano 1, v. 30, p. 75-98, jan./jun. 2005. 
SOUZA, Donaldo Bello de. Avaliação organizacional de Planos Municipais de Educação relativos ao PNE 2014-2024. Revista Estudos em Avaliação Educacional, São Paulo, vol. 28, n. 69, set./dez. 2017. p. 970-999.

SOUZA, Donaldo Bello de; ALCÂNTARA, Alzira Batalha. (Des)vinculações de Planos Municipais de Educação metropolitanos com outros instrumentos de gestão local da educação. Educação e Pesquisa, São Paulo, vol. 43, n. 3, p. 711726, jul./set., 2017b.

SOUZA, Donaldo Bello de; ALCÂNTARA, Alzira Batalha. Planos Municipais de Educação metropolitanos: desafios ao acompanhamento e avaliação local. Perspectiva, Florianópolis, vol. 35, n. 3, jul./set. 2017a. p. 758-783.

SOUZA, Donaldo Bello de; ALCÂNTARA, Alzira Batalha. O lugar dos Conselhos Municipais de Educação nos PMEs relativos ao PNE 2001-2010. Revista Educação em Questão, Natal, vol. 54, n. 40, jan./abr. 2016. p. 191-219.

VIEIRA, Sofia Lerche. Planos e políticas educacionais: das concepções às práticas. In: SOUZA, Donaldo Bello de; MARTINS, Angela Maria (Orgs.). Planos de educação no Brasil: planejamento, políticas, práticas. São Paulo: Edições Loyola, 2014. p. 55-71.

\footnotetext{
MARIA ELIZA NOGUEIRA OLIVEIRA possui Graduação em Pedagogia pela Universidade Estadual Paulista Júlio de Mesquita Filho - UNESP (2006), Mestrado (2011) e Doutorado (2015) em Educação pela mesma Universidade. Atualmente, é Docente do Mestrado em Educação da Universidade do Oeste Paulista (UNOESTE), onde desenvolve e orienta pesquisas nas áreas de Políticas e Gestão da Educação Básica e Superior. Realiza estágio pós-doutoral na Universidade Federal de São Carlos (Bolsa PNPD/CAPES-2019), integrando-se à Rede Universitas/br e ao "Observatório e pesquisa das políticas de avaliação da educação superior" (UFSCar). Integra o Grupo de Pesquisa "Estado, Políticas Educacionais e Democracia” (UNOESTE).E-mail: mariaeliza_oliveira@yahoo. com.br

ORCID: https://orcid.org/0000-0002-1771-1488
} 
TATIANE OLIVEIRA SANTOS NASCIMENTO possui Graduação em Matemática pela Universidade Estadual de Maringá - UEM (2012), especialização em Gestão Educacional pela Universidade Estadual Paulista - UNESP, Mestrado em Educação pela Universidade do Oeste Paulista - UNOESTE (2018), neste período foi bolsista do CNPq, Doutoranda em Educação pela Universidade Estadual Paulista - UNESP (2019). Atualmente é professora da rede privada no ensino básico. E-mail: tatiosn@hotmail.com

ORCID: https://orcid.org/0000-0001-5724-0732

SILVIO CESAR NUNES MILITÃO possui Graduação em Ciências Sociais pela Universidade Estadual Paulista Júlio de Mesquita Filho - UNESP (2000), graduação em Pedagogia pela Universidade Nove de Julho - UNINOVE (2008), Mestrado (2003) e Doutorado (2007) em Educação, ambos pela Universidade Estadual Paulista Júlio de Mesquita Filho - UNESP. Atualmente é Professor Assistente Doutor do Departamento de Didática da UNESP (FFC/Campus de Marília), integrando o corpo docente permanente do Programa de Pósgraduação em Educação da UNESP (FCT/Campus de Presidente Prudente). É líder do Grupo de Estudos e Pesquisas em Políticas Educacionais e Práticas Educativas (GEPPOPE). Desenvolve pesquisas na área de Políticas e Gestão da Educação, relacionadas as políticas e reformas educacionais deflagradas pelas esferas nacional, estadual e municipais e a correspondente implementação no contexto da prática. Atua no curso de Pedagogia, em disciplinas relacionadas as políticas e práticas educativas. E-mail: scnmilitao@gmail.com

ORCID: https://orcid.org/0000-0003-2094-1193

Recebido em marco de 2019

Aprovado em junbo de 2019 